\title{
'JALAN KESELAMATAN BAGI ORANG-ORANG MELAYU' : PEMIKIRAN ZA'BA BAGI MEMAJUKAN PENDIDIKAN DAN EKONOMI PADA TAHUN 1920-AN
}

\author{
Ermy Azziaty Rozali \\ Mohammad Redzuan Othman
}

\begin{abstract}
'Jalan Keselamatan Bagi Orang-orang Melayu' (The Saviour of the Malays) is an article written by Zainal Abidin bin Ahmad ( $\mathrm{Za}$ 'ba) that discusses the significance of educational and economic development of the Malays. The importance of education and uplifting economic standard is the core of the discussion of the article. In his article $\mathrm{Za}$ 'ba clearly suggests that the Malays should strive hard in order to come out from poverty and deprivation. As a visionary man, Za'ba strongly believed that the Malays has the ability to succeed provided that they strive hard for a better achievement in education, and improved their economic standard at par as other races. The suggestion and criticism by Za'ba towards the society extolling them to compete and struggle for the betterment of their live remain useful and relevant for the Malays until today.
\end{abstract}

\section{Pengenalan}

Pendidikan dan ekonomi merupakan dua aspek penting yang menjadi isu perbincangan untuk membangun dan memajukan orang Melayu sejak sebelum merdeka lagi. Walaupun kedua-dua aspek ini telah menjadi agenda utama pemimpin masyarakat Melayu sejak berdekad-dekad yang lalu, namun perbahasannya masih lagi berterusan, terutamanya dalam mendepani cabaran yang sedang dihadapi pada masa kini. Artikel 'Jalan Keselamatan Bagi Orang-orang Melayu' merupakan artikel yang ditulis oleh Za'ba yang menekankan tentang pentingnya penguasaan ilmu dan intelektual bagi membolehkan orang Melayu 'berdiri sama tinggi dan duduk sama rendah' dengan bangsa-bangsa yang lain. Artikel buah fikiran Za'ba ini telah diterbitkan oleh akhbar Al-Ikhwan pada 16 Jun dan 16 Ogos 1927 yang intipatinya secara jelas menekankan supaya orang Melayu tidak seharusnya leka, bahkan disarankan supaya menguasai pelbagai bidang keilmuan dan kemahiran untuk membangun seterusnya mengejar kemajuan. 
Di samping aspek pendidikan, satu lagi kekuatan yang perlu dibina oleh orang Melayu sebagaimana yang ditekankan oleh Za' ba adalah dalam bidang ekonomi. Orang Melayu sepatutnya mengubah sikap mereka dan bersungguh-sungguh untuk bersaing dengan bangsa lain. Walaupun perbincangan berkaitan kedua-dua aspek ini kelihatan agak klise, namun kekuatan yang terdapat dalam tulisan Za'ba adalah analisis beliau mengenai kelemahan orang Melayu yang dialami oleh orang Melayu. Selain itu terdapat juga saranan beliau terhadap beberapa langkah yang perlu dilakukan oleh masyarakat Melayu dalam memperbaiki taraf hidup. Pemikiran beliau ini boleh dianggap mendahului zamannya dan masih relevan sehingga ke hari ini. Za' ba menegaskan bahawa dengan kekuatan bidang keilmuan dan ekonomi, masyarakat Melayu berupaya membina benteng bagi kekuatan bangsa mereka untuk menjadi bangsa yang mampu bersaing dalam segenap bidang yang diceburi.

\section{Latar Belakang Kehidupan dan Sumbangan}

Zainal Abidin bin Ahmad atau lebih dikenali sebagai Za'ba, dilahirkan pada 16 November 1895 di Kampung Kerdas, Batu Kikir, Negeri Sembilan. Bapanya Ahmad bin Ibrahim merupakan keturunan Bugis, manakalanya ibunya Intan Awaluddin berasal dari suku Minangkabau.

Za'ba mendapat pendidikan agama dari ayahnya yang turut mengajar anak-anak kampung membaca al-Quran. Pendidikan formalnya bermula pada usia 12 tahun dan bersekolah di Sekolah Melayu, Kuala Jempol, Batu Kikir, Negeri Sembilan. ${ }^{1}$ Walaupun mendapat tentangan daripada bapanya, namun Za'ba meneruskan pengajiannya ke sekolah Inggeris, iaitu di St. Paul Institution, Seremban pada 10 Januari 1910. Ketika belajar di sini Za'ba mendapat biasiswa sebanyak $\$ 5.00$ sebulan dari kerajaan Negeri Sembilan ketika itu. ${ }^{2}$ Pada akhir 1915, beliau menduduki peperiksaan Senior Cambridge di Kuala Lumpur dan mencatat sejarah sebagai pelajar Melayu yang mendapat kejayaan yang cemerlang dalam peperiksaan tersebut. ${ }^{3}$ Peluang pendidikan yang diperolehinya telah membolehkan beliau menguasai tiga bahasa iaitu bahasa Arab, Inggeris dan Melayu. ${ }^{4}$

Demi mencapai matlamat memajukan pendidikan anak-anak Melayu, Za'ba telah memilih jawatan guru setelah menamatkan pengajian menenengahnya. ${ }^{5}$ Beliau berkhidmat sebagai guru di Sekolah Inggeris Bukit Zahrah dan Sekolah Inggeris Johor. Kemudiannya beliau bertukar ke Perak dan mengajar di Kolej Melayu Kuala Kangsar. Beliau mengajar di sana selama tujuh tahun, iaitu dari tahun 1916-1923. Oleh kerana pemikirannya dianggap progresif oleh pihak berkuasa dan dibimbangi akan mempengaruhi pelajar-pelajarnya, beliau ditugaskan sebagai pengarang dan penterjemah Melayu dari tahun 1923-1947. Tugas utamanya adalah menerbitkan buku teks dan buku bacaan umum di sekolah Melayu. Pada 
tahun 1947, beliau telah dilantik sebagai pensyarah di School of Oriental and African Studies (SOAS), London. Beliau bersara secara rasminya pada tahun 1951 dan seterusnya berkhidmat sebagai pensyarah kanan dan Ketua Jabatan Pengajian Melayu, Universiti Malaya, Singapura selama enam tahun (1953-1958). ${ }^{6}$

Za'ba mempunyai minat yang tinggi dalam bidang penulisan. Sejak muda lagi Za'ba telah menulis pelbagai tulisan yang berkaitan dengan kelemahan pendidikan, kemunduran dan kemiskinan orang Melayu. Selain itu beliau juga menulis tentang bahasa, budaya, sastera, akhlak dan halehwal agama. Tulisan-tulisannya tersiar dalam majalah dan akhbar berbahasa Melayu dan Inggeris seperti Utusan Melayu, Lembaga Melayu, Pengasuh, The Malay Mail, The Straits Times, Journal of the Malayan Branch of the Royal Society, Islamic Review, The Muslim dan lain-lain lagi. Antara nama samaran yang digunakan ialah Za'ba, Z, Anak Melayu Jati dan Patriot.? Di samping itu, beliau turut melahirkan rencana-rencana bagi pembangunan masyarakat Melayu terutamanya dalam Panduan Guru, al-Ikhwan dan Majalah Guru selain beberapa buah karya untuk pedoman pelajar dan guru terutamanya dalam hal karang-mengarang. ${ }^{8}$

Penulisan $\mathrm{Za}^{\prime}$ ba boleh dinilai sebagai hasil daripada pengalaman, analisis dan pengamatan beliau yang teliti dan mendalam terhadap bangsanya. Beliau yang lahir dan dibesarkan di kampung, menerima pendidikan agama, Melayu dan Inggeris serta kemudiannya bekerja di bandar amat memahami senario politik, ekonomi dan juga sosial masyarakat Melayu. Hasil daripada kesedaran politik, Za'ba mengambil pendekatan anti-kolonial dan berusaha memberi teguran kepada bangsanya. ${ }^{9}$ Teguran ini diberikan memandangkan nilai dan sikap orang Melayu amat berbeza dengan orang bukan Melayu terutamanya dalam mengejar kemajuan.

Za'ba juga dianggap sebagai tokoh yang terkenal dalam pemikiran pembaharuan, islah atau reformasi Islam, terutamanya menerusi pengaruh gurunya Sheikh Tahir Jalaluddin yang merupakan ulama Kaum Muda yang terpengaruh dengan aliran dan pemikiran reformis yang terkenal seperti Sayid Jamal al-Din al-Afghani, Muhammad Abduh dan Muhammad Rashid Ridha. Gerakan aliran ini adalah bertujuan untuk memperbaiki cara berfikir dalam kehidupan umat Islam. ${ }^{10}$

\section{Sumbangan Pemikiran Melalui Tulisan}

Penulisan mengenai peribadi dan sejarah hidup $\mathrm{Za}^{\prime}$ ba telah ditulis secara terperinci oleh Abdullah Hussain dan Khalid Hussain (1974), Mohd Taib Osman, Hamdan Hassan (1978) dan Adnan Hj. Nawang (1994). ${ }^{11}$ Manakala Ungku Abdul Aziz pula telah banyak membahaskan pemikiran Za'ba dalam aspek ekonomi dan pendidikan masyarakat Melayu. ${ }^{12}$ Justeru itu, 
tulisan ini akan lebih memfokuskan kepada sebuah artikel yang ditulis oleh Za'ba, iaitu 'Jalan Keselamatan Melayu Bagi Orang-orang Melayu'. Artikel ini merupakan salah satu daripada himpunan hasil penulisan beliau yang membincangkan mengenai permasalahan dan masa depan orang Melayu.$^{13}$ Antara artikel penting yang membincangkan isu yang berada dalam ruang lingkup yang sama ialah 'Kemiskinan Melayu', 'Guna Kekayaan', 'Teguran dan Jawaban', 'Kasihkan Diri dan Kasihkan Orang Lain', 'Keadaan Masyarakat Melayu', 'Rajin Orang China' dan lain-lain.

Berdasarkan pengetahuan dan ilmu yang dimiliki, disokong dengan penguasaan dalam bahasa Melayu, Inggeris dan Arab, Za'ba mula menulis rencana-rencana yang bermula pada tahun 1916. Ketika ini akhbar Utusan Melayu dan Lembaga Melayu mula mengeluarkan tulisan-tulisan beliau. Pada akhir tahun 1916 hingga tahun 1917, tulisannya diterbitkan secara bersambung-sambung dan disiarkan dalam akhbar Lembaga Melayu dengan judul 'Persaudaraan di Antara Ilmu, Bahasa, Bangsa, Persatuan dan Kemajuan'. Rencana ini kemudiannya telah disiarkan dalam akhbar Utusan Melayu dan mendapat sambutan hangat sehingga menyebabkan nama Za'ba semakin popular. Ini menaikkan semangat beliau untuk terus menulis terutamanya tentang kemunduran pendidikan anak-anak Melayu. Bagi beliau, menuntut ilmu adalah penting dan agama Islam mewajibkan umatnya menuntut ilmu seperti yang diajarkan oleh Nabi Muhammad S.A.W dalam hadis-hadisnya dan juga yang termaktub dalam al-Quran. Za'ba menekankan kewajipan menuntut ilmu kerana dengan ilmu akan meningkatkan martabat umat Islam. ${ }^{14}$

Za'ba juga amat prihatin terhadap kemiskinan yang dialami oleh masyarakat Melayu. Artikel beliau bertajuk The Poverty of Malays yang disiarkan dalam ruangan editorial akhbar The Malay Mail pada 1 Disember 1923 merupakan manifestasi kepada keprihatinannya terhadap masalah kemiskinan dan kemunduran yang melingkari kehidupan masyarakat Melayu. Tulisan ini diikuti dengan tulisan-tulisannya yang lain mendapat reaksi yang hebat sama ada bersetuju ataupun mereka yang menentang. Siri tulisan mengenai kemiskinan diakhiri dengan artikel yang bertajuk The Salvations of Malays. Ini kerana pihak British merasa tidak senang dengan tulisan-tulisan beliau dan beberapa langkah sekatan telah dilakukan terhadap tulisannya. Antaranya ialah kesukaran Za'ba mendaftarkan persatuan yang ditubuhkan bersama-sama teman beliau, iaitu Persekutuan Surat-suratan Melayu Kuala Lumpur (The Malay Literary Association Kuala Lumpur). Za'ba juga disiasat oleh Pegawai Cawangan Khas British mengenai kegiatan-kegiatan yang dilakukan, termasuklah tulisan-tulisan yang tersiar dalam akhbar. ${ }^{15}$

Kesan tekanan pihak British menyebabkan beliau terpaksa meninggalkan tulisan yang berkisar mengenai isu ekonomi untuk beberapa 
tahun. Pada Disember 1927, Za'ba menerbitkan semula rencana The Salvation of Malays dalam bahasa Melayu yang bertajuk 'Jalan Keselamatan Bagi Orang-orang Melayu' menerusi akhbar al-Ikhwan yang diterbitkan oleh Sayid Sheikh al-Hadi. ${ }^{16}$ Sayid Sheikh al-Hadi merupakan seorang tokoh islah yang banyak menghasilkan penulisan dalam bentuk artikel, novel, buku dan juga karya terjemahan. Penerbitan al-Ikhwan dan Saudara oleh beliau menjadi wadah menyampai maklumat dan pemikiran kepada masyarakat. ${ }^{17}$

\title{
Jalan Bagi Keselamatan Dan Kemajuan Orang Melayu
}

Jika dilihat selepas hampir lapan dekad dari tempoh pemerhatian dan penelitian Za'ba, masyarakat Melayu masih dibelenggu dengan masalah yang sama, iaitu isu kemiskinan, jurang ekonomi dan juga pendidikan. Walaupun berlaku perubahan dan pencapaian oleh masyarakat Melayu, khususnya dalam bidang ekonomi, namun secara relatifnya kemajuan mereka masih lagi di tahap yang rendah jika dibandingkan dengan bangsa lain, terutamanya kaum Cina yang mendominasi sektor ekonomi negara. Za'ba boleh dianggap sebagai anak Melayu pertama yang mengarang secara khusus tentang isu kemiskinan dan cara-cara mengatasinya. ${ }^{18}$

Jika ditinjau semula, sebelum menulis artikel 'Jalan Keselamatan Bagi Orang-orang Melayu', Za'ba terlebih dahulu menggambarkan senario kemiskinan yang dihadapi oleh bangsanya. Antara pandangan beliau adalah:

\begin{abstract}
Orang-orang kita Melayu ini pada hitungan am atau jumlahnya ialah suatu kaum yang tersangat miskin. Kemiskinan itulah sifatnya yang terlebih sangat lengkap dan nyata daripada lain-lain sifat kebangsaannya dan ialah juga sebesar-besar kekurangan menjadikan mereka kalah atau ketinggalan di belakang dalam perlumbaan kemajuan. Miskin pada wang ringgit dan harta benda, miskin pada hemat dan cita-cita, miskin pada pelajaran dan latihan pengetahuan, miskin pada alat-alat kelengkapan otak dan pada beberapa sifat keperangaian yang tinggi dan mulia maka jadilah mereka tak dapat tidak daripada tersangkut dan ketinggalan daripada perjalanan bangsa-bangsa. ${ }^{19}$
\end{abstract}

Perbahasan mengenai kemiskinan ini kemudiannya dibincangkan oleh Za'ba dengan menyingkap identiti masyarakat Melayu. Orang Melayu disifatkan:

Mewarisi beberapa tabiat perangai dan kebiasaan yang lemah dan rendah yang telah lazim pada zaman nenek-moyang dahulu kala, beratus ratus tahun lamanya mereka telah kena picit, perah dan ramas di tangan pemerintah-pemerintah daripada bangsa mereka sendiri. Oleh itu 
tentulah berkehendakkan lama juga masanya bagi menghilangkan segala kejadian-kejadian keji itu sekurang-kurangnya tiap-tiap satu kurun yang telah membawa kerosakan itu dikehendaki sesuku kurun bagi membaikinya pada zaman semua perkara cepat dan pantas ini. ${ }^{20}$

Keperitan yang dialami oleh orang Melayu membawa kepada penjelasan mengenai agenda untuk menaikkan kedudukan bangsa Melayu. Perbincangan mengenai kemiskinan Melayu diteruskan dengan langkah mengatasi masalah ini menerusi artikel 'Jalan Keselamatan Bagi Orangorang Melayu'. Berdasarkan artikel tersebut, Za'ba menjelaskan bahawa:

Bahawasanya keselamatan orang Melayu ini pada pihak jalan kehidupannya (pencariannya) dan pada pihak perangai-perangai yang kekurangan itu hanyalah boleh didapati pada satu jalan sahaja, iaitu diubati kemiskinannya yang pada pihak otak itu-yakni kemiskinan pengetahuannya dengan jalan diberi mereka itu pelajaran-pelajaran daripada jenis yang betul. Maka disitulah sahaja boleh didapati jalan keselamatan ini, tiada yang lainnya. ${ }^{21}$

Menerusi kenyataan Za'ba di atas, jelas menunjukkan bahawa aspek pendidikan merupakan elemen yang penting dalam memantapkan kedudukan orang Melayu. Di samping itu, beliau turut mencadangkan konsep bekerjasama yang membawa pengertian saling bantu-membantu dalam satu usaha yang besar dan mengikut kepakaran masing-masing. Za'ba memberikan perbandingan kejayaan pemerintahan yang adil dan makmur adalah kesan daripada kerjasama setiap bahagian dalam pemerintahan tersebut sebagaimana penghasilan sebuah pesawat itu adalah kejayaan daripada kerjasama semua tenaga pakarnya. Oleh itu, konsep kerjasama yang sedemikian diperlukan oleh orang Melayu bagi mengangkat martabat mereka ke tahap yang lebih tinggi. Di samping itu, beliau turut memberi seruan kepada masyarakat agar mempunyai sikap jimat-cermat, menjaga kesihatan, menjalankan kegiatan ekonomi secara kecil-kecilan seperti bercucuk tanam, berternak, berjual-beli dan sebagainya. Baginya galakan tersebut boleh disuarakan dalam khutbah, syarahan, nasihat dan juga penerbitan risalah-risalah kecil. ${ }^{22}$

Orang Melayu juga disifatkan oleh Za'ba sebagai bangsa yang muda dan masih mentah jika dibandingkan dengan bangsa yang maju dan tinggi kedudukannya. Namun begitu, faktor tersebut tidak wajar dijadikan kekangan untuk mereka bangkit dan pantas berusaha mengejar kemajuan. Pandangan orang yang menyeru supaya bersabar dan tidak gopoh itu sebenarnya tidak mempunyai cita-cita dan hasrat untuk melihat bangsanya maju. ${ }^{23}$ Namun begitu, Za'ba menegaskan bahawa sebarang usaha kerjasama yang dilakukan untuk memajukan bangsa Melayu hendaklah 
mengutamakan aspek pendidikan sebagai asas mengangkat martabat orang Melayu. Langkah untuk mengejar kemajuan adalah memberikan penekanan dalam bidang pendidikan. ${ }^{24}$

Seruan dilontarkan supaya mengubah kemiskinan perangai mereka dengan sifat-sifat yang dapat memajukan diri mereka. Sifat-sifat yang telah digariskan ialah self reliance (bergantung kepada diri sendiri), preseverance (teguh dalam cita-cita), sense of responsibility (merasa bertanggungjawab), sense of duty (menyempurnakan tugas), punctuality (menepati masa), industry (kuat bekerja), self sacrifice (berkorban) dan public spirit, (mengambil berat kebajikan umum). Kesemua sifat-sifat yang dicadangkan ini adalah penting untuk merawat penyakit kemiskinan bangsa Melayu. ${ }^{25}$

Za'ba juga mengulas mengenai pendidikan bagi sesuatu bangsa dalam pelbagai aspek:

Pelajaran otak atau kepandaian-kepandaian sekolah atau kolej sahaja, istimewa pula jika yang demikian itu terlalu rendah dan tiada melebihi daripada kepandaian membaca, menulis, berkira-kira dan membuat kerja-kerja kerani dan mengenal akan kesedapan karangan-karangan yang rendah dan kecil. Pelajaran yang dikatakan cukup itu hendaklah termasuk di dalamnya pelajaran-pelajaran berniaga, berjual-beli, pertukaran, membuat barang-barang, bercucuk tanam dan berbagaibagai perusahaan dan pekerjaan mengeluarkan hasil. Dalam pada itu hendaklah pula dimaksudkan tiap-tiap seorang termesti belajar dan mengetahui kesemuanya itu. ${ }^{26}$

Berdasarkan kenyataan ini, jelas menunjukkan Za'ba mempunyai pandangan luas dalam memberikan pengertian pelajaran ataupun pendidikan untuk orang Melayu. Baginya, pendidikan amat penting dalam mengubah nasib sesuatu bangsa selain pencapaian akademik, penguasaan bidang-bidang kemahiran dan vokasional juga penting untuk dikuasai bagi menjamin kemajuan dan kecemerlangan bangsa. Apabila tahap pendidikan yang baik dimiliki, secara tidak langsung akan dapat meningkatkan kedudukan sesuatu bangsa itu. Menurut pengamatan Za'ba, sikap dan tabiat orang Melayu adalah berlawanan dengan sifat-sifat di atas. Oleh itu, masyarakat Melayu hendaklah membuang sikap-sikap negatif dan digantikan dengan sikap yang boleh membawa kemajuan. Justeru, golongan muda sewajarnya mendapatkan pendidikan yang baik dan seterusnya memikul tanggungjawab untuk memberi kesedaran, menggerakkan diri dan bangsanya ke arah kemajuan. ${ }^{27}$

Pendidikan agama yang kolot dan cetek yang tidak selari dengan kehendak syariat Islam yang sebenarnya juga menjadi kekangan kepada orang Melayu mencapai kemajuan. Beliau menyatakan bahawa: 
Sekiranya tiada berpelajaran nescaya tetaplah juga mereka (orang Melayu) ini seperti kead aannya sekarang serta berkekalan lagi demikian itu dari satu keturunan kepada satu keturunan iaitu sebenar-benar katak di bawah tempurung, baikpun orang alimnya dan jahilnya serupa sahaja, tidak pernah terlintas di muka hati mereka itu apa erti kemajuan. Orang alim mereka tidak pernah terfikir mengatakan ada ilmu-ilmu lain yang lebih luas daripada kulit-kulit agama yang telah kering yang diketahui oleh mereka sedikit-sedikit itu, dan orang-orang jahilnya pula tiada tersangka ada orang-orang lain yang lebih 'alim' daripada tuan-tuan guru dan tuk-tuk syeikh tarekatnya yang 'alim besar' dan 'keramat' masing-masing itu ${ }^{28}$

Penguasaan ilmu merupakan faktor penting untuk mengubah sikap orang Melayu. Oleh itu, untuk menampung kelemahan tersebut, maka menjadi kewajipan kepada orang Melayu, terutamanya golongan muda menguasai bidang ilmu. Tanpa penguasaan ilmu, masyarakat Melayu akan kekal ketinggalan dan berterusan sehingga generasi akan datang. Usaha untuk meningkatkan pendidikan orang Melayu memerlukan peraturan yang besar yang melibatkan pentadbiran kerajaan dan asasnya adalah bersatu, bekerjasama dan tolong-menolong. Orang Melayu yang benarbenar berhasrat menghasilkan jalan keselamatan bagi bangsanya tidak harus gentar dengan cabaran. Walau bagaimana susah dan sukarnya citacita tersebut, ia tidak mustahil boleh dicapai jika bersatu antara satu sama lain. ${ }^{29}$

Di samping itu, orang Melayu diseru agar menguasai ilmu yang meliputi pelbagai bidang serta melibatkan diri dalam pelbagai pekerjaan seperti bidang kedoktoran, kejuruteraan dan undang-undang. Di samping itu, bidang perniagaan, pertanian dan industri pembuatan harus juga diceburi oleh masyarakat Melayu. Untuk melaksanakan rancangan tersebut, ia tidak hanya memerlukan sumber kewangan yang banyak, malah dari segi spiritualnya juga memerlukan sikap amanah, tanggungjawab dan juga keikhlasan. Cadangan yang disyorkan ini haruslah disempurnakan kerana di sinilah terletaknya jalan keselamatan bagi orang Melayu. Sekiranya tindakan tidak dilakukan sekurang-kurangnya 200 tahun lagi barulah bangsa Melayu mengecap kemajuan atau sebaliknya terus terpinggir kesan persaingan daripada bangsa-bangsa lain. ${ }^{30}$

Galakan membentuk kerjasama juga dicadangkan dengan wujudnya golongan yang menggerakkan kerjasama dalam kalangan masyarakat Melayu. Kumpulan sasaran yang dimaksudkan adalah golongan ilmuan dan juga yang mempunyai sumber kewangan atau kedudukan yang tinggi. Kedua-dua golongan ini hendaklah bersatu-padu untuk mengurangkan kadar kemiskinan yang dialami oleh orang Melayu dengan ilmu dan sumber kewangan yang dimiliki. Bangsa Melayu tidak sewajarnya menjadi 
bahan ejekan dan sindiran oleh negara yang maju. Oleh itu masyarakat Melayu harus bekerja keras untuk membuktikan kepada dunia bahawa mereka juga boleh mendapat kedudukan yang lebih tinggi atau setidaktidaknya berdiri sama tinggi dengan bangsa-bangsa lain.

Za'ba juga menegaskan bahawa cadangan beliau ini boleh diperhalusi lagi dan dibuat penambahbaikan dengan memberi pandangan dan fikiran masing-masing. Oleh itu, masyarakat Melayu diseru agar bangkit daripada tidur. Begitu para pemimpin seharusnya tidak leka dengan kemewahan sendiri tanpa memikirkan kepentingan masyarakat umum. Walaupun persatuan dan kelab Melayu telah banyak diwujudkan, namun tidak banyak aktiviti yang dijalankan dapat membina pembangunan ahlinya. Aktiviti kelab tersebut lebih berbentuk hiburan, manakala aktiviti berbentuk keagamaan pula hanya berkisar kepada acara berzanji, marhaban dan melagukan qasidah. Guru-guru agama juga terikat kepada pengkajian kitab-kitab jawi yang hanya berkisar kepada perkara sah, batal, haram dan dosa pahala dan tidak sampai kepada ilmu-ilmu yang menjadi asas ajaran Islam seperti tafsir, hadith, syariah dan juga sejarah. ${ }^{31}$ Oleh itu, menjadi kewajipan kepada orang Melayu untuk membuang kelemahan ini dan digantikan dengan pendidikan yang dapat mengubah generasi muda yang mungkin menjadi pemangkin kepada bangsanya untuk maju ke hadapan. Matlamat tersebut dapat dicapai dengan penguasaan ilmu, perpaduan dan kerja yang kuat dalam kalangan masyarakat Melayu. Za'ba juga mencadangkan bahawa:

Suatu kumpulan daripada anak-anak negeri kita hendaklah diberi pelajaran yang luas dan tinggi, setengahnya pada pihak kepandaian ilmu-ilmu siasat kejadian dan fikiran-fikiran yang tinggi dan setengahnya pada pihak kepandaian ilmu-ilmu siasat yang khas bagi pekerjaan mengambil upah dan mencari wang seperti berlawyer, berengineer, berdoktor dan lain-lain lagi. Maka tidaklah pula dikehendaki kesemuanya berkerumun hendak menjadi lawyer atau menjadi doktor ataupun engineer, tukang injin, tukang elektrik atau pegawai-pegawai yang memerintah negeri melainkan pilihlah masing-masing ikut kecenderungan. Mana yang cenderung pada yang berniaga dan bersaudagar hantarlah belajar pasal perniagaan, peraturan dan sebagainya. Mana yang ada berkecenderungan fasal tukang menukang dan membuat barang-barang berilah pula pelajaran pada perkaraperkara itu. Kekayaan sumber dan hasil bumi negeri ini boleh dijadikan modal untuk orang-orang Melayu bersaing dengan bangsa-bangsa lain. ${ }^{32}$

Ketiga-tiga kelemahan masyarakat Melayu iaitu kemiskinan, keadaan puas hati dan kesederhanaan boleh diperbaiki jika diberi pendidikan yang lebih baik. Menerusi pendidikan, mereka mempunyai keyakinan diri 
sendiri (berdikari). Pekerja Melayu akan menjadi lebih layak untuk sektor perindustrian, perdagangan dan juga untuk jawatan ikhtisas dalam bidang undang-undang, perubatan, kejuruteraan dan jawatan-jawatan tertinggi kerajaan yang mana memerlukan ijazah daripada universiti. Jika orang Melayu sentiasa bersikap berpuas hati, maka ia adalah berpunca daripada diri mereka yang tidak mempunyai kelayakan yang tinggi untuk mara ke hadapan. ${ }^{33}$

Za'ba juga turut mengkritik peranan golongan pemimpin yang dilihat tidak banyak membantu orang-orang Melayu. Walaupun penubuhan kelab dan persekutuan di seluruh Semenanjung mencecah ratusan buah tetapi mereka tidak berperanan sebagaimana sewajarnya. Sebaliknya, mereka hanya melakukan aktiviti yang kurang berfaedah seperti perhimpunan terup, main dam atau billiard ataupun menghabiskan masa dengan berbual perkara yang tidak berfaedah selain mengadakan permainan tenis atau bola sepak yang digemari oleh orang Melayu. ${ }^{34}$ Komentar yang diberikan oleh Za'ba ini menunjukkan rasa tidak puas beliau terhadap kelab dan persekutuan yang ditubuhkan oleh orang Melayu kerana tidak memainkan peranan dalam memajukan bangsanya.

Orang Melayu juga dinasihati agar tidak ternanti-nanti munculnya wira ataupun tokoh-tokoh reformasi yang akan lahir daripada bangsa Melayu sebagaimana kemunculan tokoh-tokoh hebat bangsa lain seperti Napoleon Bonarparte, Mustafa Kemal Pasha, Redza Khan ataupun Rabindranath Tagore. Ini kerana belum pernah didengari bangsa Melayu melahirkan tokoh dan wira mereka sebelum ini kerana secara relatifnya kita masih lagi muda berbanding bangsa-bangsa lain. Oleh itu, kita sebaliknya:

Hendaklah berkeledar sendiri dengan berdikari dan berusaha bersungguh-sungguh. Pertolongan itu hendaklah terlebih dahulu diperbuat dari sebelah dalam diri kita, kemudian baharulah boleh kita mengharap-harapkan pertolongan datang dari sebelah luar diri kita. Maka nyatalah tiada berfaedah sekali-kali kita meminta doa barang sesuatu apa kepada Tuhan dan memohonkan pertolongannya jikalau kita tiada menunjukkan kita layak mendapat barang yang kita pinta itu. ${ }^{35}$

Pengiktirafan Za'ba terhadap Mustafa Kemal dapat dikaitkan dengan minat dan kecenderungan beliau terhadap daulah Turki Uthmaniyah selain turut berminat dengan persoalan khilafah di Istanbul. Beliau berpendapat bahawa kedudukan khilafah mestilah dikekalkan dan pihak British harus menghormati dan mengiktiraf Istanbul sebagai bandar Islam. Za'ba menyokong tindakan umat Islam di India dalam Gerakan Khilafah yang membantah campurtangan British dan menuntut keadilan ke atas mereka. ${ }^{36}$ Beliau juga mengkategorikan tiga golongan intelektual Melayu. Golongan 
tersebut ialah Kaum Muda, Kaum Tua dan yang ketiga adalah golongan yang berpendidikan barat. Sikap golongan ini terhadap agama Islam adalah menyamai pemimpin Turki dan dianggap terpengaruh dengan revolusi Kemal. Antara tokoh terkenal dalam kategori ini ialah Tunku Abdul Rahman, Perdana Menteri Malaysia yang pertama. Beliau dilihat begitu menyokong nasionalisme Kemal. ${ }^{37}$

Untuk berhadapan dengan persaingan hebat dalam dunia sekarang ini, orang Melayu sekarang harus mengambil iktibar daripada pesanan Za'ba yang mengingatkan orang Melayu agar tidak leka dan merasa selesa dengan apa yang mereka miliki kerana sikap tersebut tidak akan membawa mereka maju ke hadapan. Beliau menjelaskan bahawa orang Melayu hendaklah menggerakkan diri mereka yakni berusaha dan bekerja untuk memberikan pendidikan yang lebih tinggi kepada bangsanya. Dalam menggerakkan diri itu bukanlah bererti meminta semua perkara daripada kerajaan tetapi hendaklah menunjukkan kelayakan diri kita dahulu. Baginya agak kurang manis sekiranya menjadikan diri kita peminta sedekah pada semua perkara yang menjadi kewajipan kita sendiri. Baginya bangsa Melayu hendaklah cuba berikhtiar dalam urusan pekerjaan dunia selain berdoa dan meminta pertolongan daripada Allah. ${ }^{38}$

Terdapat beberapa cadangan yang telah disyorkan oleh Za'ba dalam usaha melaksanakan konsep kerjasama dalam kalangan orang Melayu. Antaranya ialah membangunkan persekutuan ataupun kesatuan yang bertindak mengumpulkan dana kewangan. Hasil daripada kutipan dana tersebut akan disalurkan kepada pelajar-pelajar Melayu yang miskin untuk melanjutkan pengajian ke peringkat lebih tinggi.

Di samping itu, Za'ba turut menyarankan agar terdapat usaha menubuhkan kesatuan untuk menyediakan latihan-latihan kemahiran kepada golongan muda yang tidak mempunyai pendidikan yang tinggi. Ini kerana masih terdapat pemuda Melayu yang berminat untuk melakukan pekerjaan selain menjadi pekerja mengukur tanah dan penoreh getah. Kemahiran tersebut adalah seperti pertukangan besi dan emas, jahitan, pembuatan, kasut, pertukangan kayu dan lain-lain kemahiran untuk mencari pendapatan. Tenaga pengajar boleh diambil daripada bangsa lain seperti bangsa Cina untuk mengajar anak-anak Melayu kemahiran tersebut.

Bagi meningkatkan aspek pendidikan, Za'ba mencadangkan agar diwujudkan kesatuan yang dapat menjana dana yang besar seperti Queen Scholarship di Negeri-Negeri Selat untuk menyediakan biasiswa bagi membiayai pendidikan anak-anak Melayu yang bijak. Melalui bantuan yang diberikan mereka yang mencapai kelulusan yang tinggi, bolehlah dihantar ke negara luar seperti Eropah, Amerika dan sebagainya bagi menyambung pengajian dan menimba ilmu pengetahuan. 
Di samping itu, Za'ba mencadangkan supaya diwujudkan perbahasan dan juga wacana keilmuan dalam dua tiga kali sebulan untuk menaikkan semangat orang Melayu agar berani dalam pidato umum. Aktiviti seperti penulisan buku, penterjemahan sama ada dalam bahasa Inggeris ataupun bahasa lain ke dalam bahasa Melayu. Buku-buku yang disediakan hendaklah dapat memberikan pengetahuan umum yang berguna seperti ilmu sejarah, karangan yang hebat dari zaman dahulu dan juga pengajian agama seperti Daqaiqul Akhbar, Qasasul Anbia' dan Manaqib Syed Abdul Kadir al-Jailani. Walau bagaimanapun tidak digalakkan tulisan yang mempunyai cerita dongeng ataupun cerita-cerita karut. Hasil penulisan tersebut diterbitkan untuk faedah orang Melayu. Za'ba juga menggalakkan penyertaan dalam persekutuan dan kesatuan yang dapat memberikan bantuan, sokongan dan juga sumbangan kepada masyarakat Melayu. ${ }^{39}$

Menerusi tulisan-tulisan yang dihasilkan jelas menunjukkan bahawa beliau mempunyai pandangan yang jauh ke hadapan dan juga memiliki keberanian. Keberanian di sini terbukti apabila beliau dengan lantang menyuarakan masalah dan nasib orang Melayu walaupun mendapat tekanan daripada penjajah British. Pemikirannya jelas dan beliau menyedari bahawa kemiskinan adalah masalah yang meresap dan berakar umbi dalam kalangan orang Melayu. Beliau juga mengemukakan sebab-sebab kemiskinan yang terdiri daripada faktor ekonomi dan bukan ekonomi. Beliau mencadangkan dua cara untuk mengatasi masalah kemiskinan, iaitu menekankan aspek pendidikan dan kerjasama menerusi koperasi. ${ }^{40}$ Walaupun dua aspek tersebut nampak klise dan biasa tetapi sejauh manakah keduanya diangkat dan dilaksanakan sehingga kini untuk meninggikan martabat orang Melayu. Ungku Abdul Aziz yang melakukan kajian terhadap pemikiran ekonomi Za'ba, memberikan penghormatan kepada tokoh ini sebagai bapa atau pengarang tertua yang membincangkan konsep kemiskinan Melayu. ${ }^{41}$

Setelah meneliti pemikiran Za'ba dalam menghadapi permasalahan masyarakat Melayu, beberapa penganalisaan dapat dibuat. Beliau begitu memahami kelemahan serta kekurangan masyarakat Melayu dan kritikan yang diutarakan tidak hanya ditujukan kepada golongan masyarakat awam, bahkan kepada golongan elit dan para pemimpin. Za'ba juga menetapkan bahawa pendekatan yang paling penting dilakukan oleh orang Melayu untuk melakukan perubahan adalah menerusi penguasaan pelbagai disiplin ilmu menerusi bidang pendidikan dan kemahiran, di samping meningkatkan percapaian agar mampu bersaing dengan bangsabangsa lain.

Pengenalan konsep kerjasama dibentangkan secara komprehensif oleh Za'ba, disertai langkah perlaksanaan agar dapat diaplikasikan oleh masyarakat Melayu. Masyarakat Melayu juga diseru menceburi pelbagai 
bidang ilmu sama ada bidang ikhtisas, kemahiran, perniagaan dan bersungguh-sungguh untuk mencari jalan keluar bagi mengangkat martabat bangsanya. Beliau juga menegaskan bahawa "kita diberi balasan hanya sukat sebanyak yang kita usahakan sahaja". Anjakan paradigma juga harus dilakukan dengan membuang sikap warisan nenek-moyang yang berlawanan dengan sikap rajin, bekerja bersunguh-sungguh dan bersemangat tinggi. Pegangan agama yang sempit yang tidak membantu untuk mengejar kemajuan dan juga kecemerlangan hendaklah dihapuskan.

\section{Kesimpulan}

Secara keseluruhannya, dapat dilihat bahawa Za'ba mempunyai pemikiran yang jauh ke hadapan yang melangkaui zamannya. Za'ba melihat dan memahami hati budi perilaku bangsa Melayu. Beliau seorang pemikir Melayu yang pertama menulis tentang masalah ekonomi orang Melayu di samping memikirkan jalan keselamatan bagi orang Melayu. Beliau juga mempunyai kesedaran dan kefahaman yang mendalam mengenai masalah orang Melayu. Menerusi kefahaman tersebut membuatkan beliau tampil melalui tulisan-tulisan yang tersirat dengan kritikan yang tajam dan bernas. Pemikirannya mengenai masalah yang dihadapi oleh orang Melayu jelas dan beliau menyedari kemiskinan adalah masalah yang sekian lama membelenggu orang Melayu.

Justeru itu sudah sewajarnya kita menilai semula pemikiran yang dibentangkan oleh Za'ba ini. Walaupun secara dasarnya cadangan yang dikemukakan oleh beliau bukanlah sesuatu yang baru, namun dua aspek tersebut iaitu pendidikan dan kerjasama yang dibahaskan oleh $\mathrm{Za}$ 'ba dengan teliti dan mendalam adalah tunjang utama terhadap penyelesaian isu kemiskinan dan ekonomi yang masih lagi menjadi permasalahan masyarakat Melayu sehingga sekarang. Penambahbaikan boleh dilakukan dalam mengimplementasikan langkah-langkah tersebut agar bersesuaian dengan perkembangan dunia teknologi dan maklumat masa kini. 


\section{Nota}

1 Abdullah Hussain \& Khalid Hussain, Pendita Za'ba Dalam Kenangan, Kuala Lumpur: Dewan Bahasa dan Pustaka, 1974, hIm . 16-17.

2 Adnan Hj. Nawang, Za'ba Patriot dan Pendeta Melayu, Kuala Lumpur: Yayasan Penataran Ilmu, 1994, hlm. 48.

3 Ibid., hlm. 57.

4 Arba'iyah Mohd Noor, "Pemikiran Pendidikan Za'ba", Jurnal Purba, Bil. 19, 2000, hlm. 17.

${ }^{5}$ Ibid., hlm. 18

' Adnan Hj Nawang, "Za'ba dan Orang Melayu', dalam Wan Abdul Kadir (sunt.), 100 Tahun Za'ba, Zaba: Pejuang Bangsa, Kuala Lumpur: Akademi Pengajian Melayu, Universiti Malaya, 1996, hlm. 1.

7 Amat Juhari Moain, "Strategi Kesinambungan Titisan Warisan Pendeta Za'ba : Peranan Sekolah", dalam Abdul Hamid Mahmood et.al, Memartabatkan Warisan $Z a^{\prime} b a$, Tanjong Malim : Penerbit Universiti Pendidikan Sultan Idris, 2004, hlm. 65.

8 Arba'iyah Mohd Noor, "Pemikiran Pendidikan Za'ba", hlm. 24.

${ }^{9}$ Mohd Taib Osman \& Hamdan Hassan (sunt.), Bingkisan Untuk Pendita, Kuala Lumpur : Dewan Bahasa dan Pustaka, 1978, hlm. viii.

${ }^{10}$ Wan Zailan Wan Kamaruddin, "Za'ba dan Pemikiran Islam", dalam Wan Abdul Kadir (sunt.), 100 tahun Za'ba, Za'ba: Pejuang Bangsa, Kuala Lumpur: Akademi Pengajian Melayu, Universiti Malaya, 1996, hlm. 286.

${ }^{11}$ Lihat Abdullah Hussain dan Khalid Hussain, "Pendita Za'ba dalam Kenangan", Kuala Lumpur : Dewan Bahasa dan Pustaka, 1974, Mohd Taib Osman \& Hamdan Hassan (sunt.), Bingkisan Untuk Pendita, Kuala Lumpur: Dewan Bahasa dan Pustaka, 1978 dan Adnan Hj. Nawang, Za'ba Patriot dan Pendeta Melayu, Kuala Lumpur : Yayasan Penataran Ilmu, 1994.

${ }^{12}$ Ungku Abdul Aziz meneliti pemikiran Za'ba dalam aspek ekonomi dan pendidikan masyarakat Melayu di samping merumikan beberapa tulisan-tulisan Za'ba, termasuklah artikel 'Jalan Keselamatan Orang-Orang Melayu'. Lihat Ungku Abdul Aziz, Jejak-jejak di Pantai Zaman, Kuala Lumpur : Penerbit Universiti Malaya, 1987.

${ }^{13}$ Al-Ikhwan, 16 Jun 1927, 16 Julai 1927, dan 16 Ogos 1927, September 1927.

${ }^{14}$ Amat Juhari Moain," Strategi Kesinambungan", hlm. 67.

${ }^{15}$ Ibid.

${ }^{16}$ Ungku Abdul Aziz, Jejak-Jejak di Pantai Zaman, hlm. viii.

${ }^{17}$ Adibah Sulaiman dan Ezad Azraai Jamsari, "Falsafah Pemikiran Syed Sheikh Ahmad al-Hedy : Akal dalam Intelektualisme dan Kemajuan Melayu", Kertas kerja yang dibentangkan dalam Nadwah Ulama Nusantara III, anjuran Fakulti Pengajian Islam, UKM dan Majlis Agama Islam Pulau Pinang, 15-17 2006, hlm. 45.

${ }^{18}$ Ungku Abdul Aziz, Jejak-Jejak di Pantai Zaman, hlm. viii.

${ }^{19}$ Zainal Abidin bin Ahmad, "Kemiskinan Melayu", al-Ikhwan, 16 Mac 1927, hlm. 132.

${ }^{20}$ Ibid., 16 April 1927, hlm. 151. 
${ }^{21}$ Zainal Abidin Ahmad, "Jalan Keselamatan Bagi Orang-orang Melayu", AlIkhwan, 16 Jun 1927, hlm. 187.

${ }^{22}$ Ibid., hlm. 188-189.

${ }^{23}$ Ibid., hlm. 191.

${ }^{24}$ Ibid., hlm. 190.

${ }^{25}$ Ibid., hlm. 213-214.

${ }^{26}$ Ibid., hlm. 216.

${ }^{27}$ Zainal Abidin Ahmad, "Jalan Keselamatan Bagi Orang-orang Melayu", AlIkhwan, 16 Ogos 1927, hlm. 229.

${ }^{28}$ Ibid., hlm. 229-230.

${ }^{29}$ Ibid., hlm. 231.

${ }^{30}$ Ibid.

${ }^{31}$ Ibid., hlm. 229.

${ }^{32}$ Ibid.

${ }^{33}$ Ungku Abdul Aziz, Jejak-Jejak di Pantai Zaman, hlm. 15.

${ }^{34}$ Ibid., hlm. 95.

${ }^{35} \mathrm{Ibid} ., \mathrm{hlm} .232$.

${ }^{36}$ Adnan Nawang, Za'ba dan Melayu, Kuala Lumpur: Berita Publishing Sdn. Bhd, 1998, hlm 201 dan Za'ba Patriot dan Pendeta Melayu, Kuala Lumpur: Yayasan Penataran Ilmu, 1994, hlm. 110 yang dipetik daripada Utusan Melayu, 20 Oktober 1919 dan Utusan Melayu, 27 September 1919. Di India, tarikh 17 Oktober 1919 dikenali sebagai 'Hari Khilafah'. Pada hari tersebut masyarakat Islam menutup sementara perniagaan mereka, ibadat dan amalan berpuasa dilakukan. Organisasi politik dibentuk untuk mempertahankan daulah Turki Uthmaniyah. Lihat Abdul Hamid, Muslim Separatism in India 1858-1947 A Brief Survey, Lahore: Oxford University Press, 1967, hlm. 133-135.

${ }^{37}$ Menurut Abdul Rahman Abdullah, golongan yang dikategorikan 'golongan Turki' ini menjadi barisan pimpinan parti United Malays National Organization (UMNO) yang berjaya memperjuangkan kemerdekaan Malaysia. Sebagaimana Kemal, kepimpinan UMNO menolak peranan agama dalam aspek politik. Golongan ini juga dikelaskan sebagai moden dan mempunyai idea-idea yang progresif dan berhubung dengan aspek agama. Perdana Menteri Malaysia ke-4, Tun Dr. Mahathir Mohamed juga termasuk dalam kalangan pemimpin yang mengkagumi Kemal dalam sejarah kebangkitan Turki. Menurut beliau jika tidak kerana kejayaan Kemal merebut Anatolia, sudah pasti tidak timbul kebangkitan Islam di Turki. Berasaskan fahaman sekularisme juga, Tun Dr. Mahathir sering menekankan agar tidak mencampuradukkan antara agama dan politik. Lihat Abdul Rahman Abdullah, Pemikiran Islam di Malaysia, hlm. 166-168 dan Za'ba, "The Malays and Religion", dalam Tamadun Islam di Malaysia, Khoo Kay Kim et. al (sunt.), Kuala Lumpur: Persatuan Sejarah Malaysia, 1980, hlm. 110 dan Mohammad Redzuan Othman, The Middle Eastern Influence on the Development of Religious and Political Thought in Malay Society 1880-1940, Tesis PhD. Universiti Edinburg, 1994, hlm. 223.

${ }^{38}$ Ibid., hlm. 232-233.

${ }^{39}$ Ungku Abdul Aziz, Jejak-Jejak di Pantai Zaman, hlm. 91-92. 
${ }^{40}$ Ibid., hlm. 24.

${ }^{41}$ Ibid., hlm. 38. 